ISBN 978-981-14-1684-2

Proceedings of 2019 the 8th International Workshop on Computer Science and Engineering

(WCSE 2019 SUMMER)

Hong Kong, 15-17 June, 2019, pp. 21-25

doi: $10.18178 /$ wcse. 2019.06 .004

\title{
Intention to Become Digital Startups
}

\author{
Wornchanok Chaiyasoonthorn $^{+}$ \\ Faculty of Administration and Management \\ King Mongkut's Institute of Technology Ladkrabang \\ Bangkok, Thailand
}

\begin{abstract}
This research aims to study the intention to become digital startups and to explore factors affecting the motivation of being digital startups. The theory of planned behavior (Ajzen's model) was operationalized to predict intention to become digital startups. The sample in this research is 400 undergraduate students in Thailand which were selected by using a convenience sampling method. The multiple linear regression was used for hypothesis testing. Research findings indicate that attitude toward the behavior, subjective norm, and perceived behavioral control positively affects the intention to become digital startups. The most significant variable in predicting the intention is the subjective norm while perceived behavioral control and attitude toward the behavior follow. The contributions of this study encourages people who intend to be a startup joining training programs and surrounding social norm such as mentor, role model, and significant others will leverage more intention to become digital startups.
\end{abstract}

Keywords: digital startups; technology startups; intention to become startups; and TPB;

\section{Introduction}

Startup business is a kind of entrepreneur, which create innovations and new business platforms to leverage the daily life of consumers. In many countries, startups play an essential role in improving societies and represent a powerful engine driving the country's economy [1], [2]. In Thailand, startups were recognized since 2015 to the present, it was started when the Thailand government has announced a creative economy policy. This policy aims to encourage people to create new ideas and change the business processes also known as an innovative economy [3], [4]. Undergraduate students are the target audience because they are going to have their career. They could choose to have their own business or work in some companies [5]-[9]. Even though they are new in working, but they were born in disruptive technology generation, so they have the digital skill. The digital skills come with new ideas and new guidelines for helping work processes better than the past [2]. The digital ability then brings the opportunity for developing innovations which eventually contributes to the society well-being.

Furthermore, Thailand's policy has announced the digital startup ecosystem builder which concluded many sub-organizations to push up and create a country from an agricultural and industrial economy to be an innovative economy [10]. Also, Thailand 4.0 aimed at 3 points: 1) creating the richness of people to get rid of the middle-income tap country, 2) being sustainable by ourselves, create technology by Thai people, and 3) to be a social welfare state for generating well-being of individuals and societies [11], [12]. However, by creating a new invention, digital startups should be aware of intellectual property and patents [13].

Digital startups are businesses who create digital technology innovations such as internet of things, smart agricultural or smart farm, inventions, and digital processes in many areas of industries. Digital startups could relate to E-commerce, FinTech, LogisticTech, and E-payment so they could motivate investors' attention [14].

\footnotetext{
+ Corresponding author. Tel.: + 663298459 fax: +663298461 .

E-mail address: wornchanok.ch@kmitl.ac.th.
} 
The difference between digital startups and small businesses is the objective, small businesses are driven by profitability, while startups focus on growth potential [15]. Typically, SME start with their investment, but digital startups come with ideas, then the ideas can be introduced to motivated people who believed in and bought those ideas by investing money in the business. To be the startups, it must be detailed in the business plan [16] since it will be the written guidelines or operational manual for every step of doing business. The startup owners could predict what should they do or should not do in each situation. So, the startups could sell their ideas and getting funds through the business plan.

Also, the significant difference between the startups and small and medium enterprise is fund or money. Usually, SMEs invest in the business by their own money, but startups invest by selling their ideas to investors such as banks, public and private organizations. The investors who invest in startups companies called venture capitals: VC [17]. According to Thailand as the seas' emerging startup hub addressed Thailand is strategically location of attracting startups because Thailand is the second largest economic value in ASEAN [14] with GDP grow by $3.9 \%$ in 2019 and expected growth by $3.7 \%$ in 2020 [18]. Also, private and public sectors have developed infrastructure to facilitate startup business processes. Moreover, in Thailand has a large customer base which makes more attractive foreign startup and investors. Meanwhile, the challenges of starting startups business in Thailand are smaller fund size and complicated established process for foreigners [14].

Although being a startup is very interesting, statistical data shows that startup exits within a few years after establishing business[19]. Therefore, it is the researcher examines the startup life cycle process related to the motivation to become startups.

\section{Literature Review and Hypothesis Development}

Theory of planned behavior (TPB) was proposed by Ajzen in 1985. This theoretical model reflects human behavior which indicates human behavior and influenced by the intention of people causing affect the action or expression of humans [20]. Ajzen stated that the intention was caused by three main factors: attitude toward the behavior, subjective norm, and perceived behavioral control which can be described as a diagram of the relationship of factors in the TPB as shown in Fig. 1

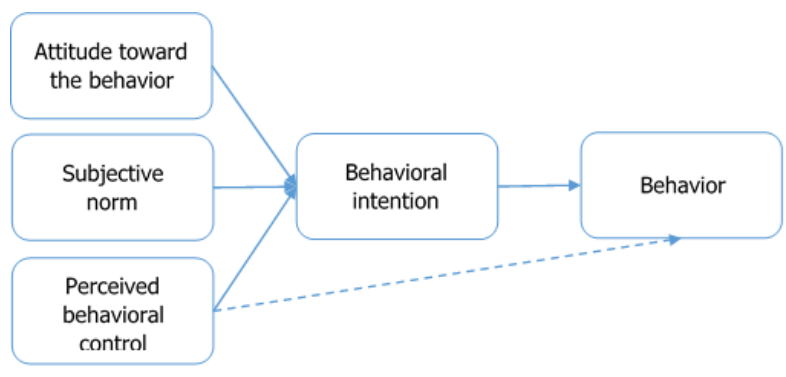

Fig. 1: Theory of planned behavior (TPB) cited by Ice Ajzen.[21]

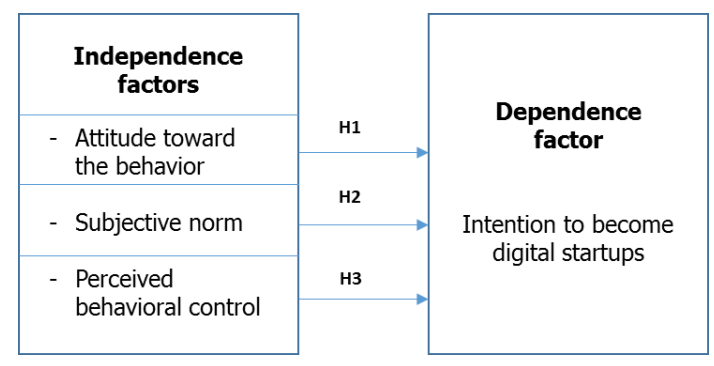

Fig. 2: The conceptual framework

Fig. 1 shows that attitude directly affects the behavioral intention. In general, an attitude is a form of assessing the concept of a person. If that person has a positive attitude towards any behavior or action means that the attitude has a positive effect on those behaviors. On the other hand, if the person has a negative attitude, causing an impact on non-action.

The attitude associated with being a digital startup entrepreneur can be determined from the perspective of a person who is an entrepreneur, such interests of individual with a sense of fun, happy and have a desire to be an entrepreneur, considering the advantages and disadvantages of being an entrepreneur, efforts to strive for entrepreneurship, feeling like to be an entrepreneur. Furthermore, an attitude factor can be measured from how they think about able to be in pressure situations, be prepared to fight or act in stressful situations. Including they think that they could endure the success even take a long time to prove [22]-[25]. Therefore, the researcher has determined the research hypothesis as follows:

H1: Attitude toward the behavior positively affects intention to become digital startups. 
The second factor is the subjective norm that refers to the conformity of the reference group, also called the person's norms arising from society or the environment. Subjective norm is a factor according to the reference group. Subjective norm arises from the perception and needs of society and closers toward individuals that should act or not do the behavior. Recognition of the perception of society and closers are resulting in the belief of the person that they should be done or not. The examples of those who have close contact with a person such as a family member, famous people in society, and the person who has respect. Feelings and beliefs will result in behavior. These beliefs have both positive and negative influences.

The subjective norm of people involved in entrepreneurship can be determined by feelings of conformity or beliefs that are close to or binding, such as family members, friends, respected people, seniors, juniors, teachers, or famous people in society [22]-[25]. Therefore, the researcher has determined the research hypothesis as follows:

$\mathrm{H} 2$ : Subjective norm positively affects intention to become digital startups.

The third factor is the perceived behavioral control which means the ability to control their behavior. This factor represents the recognition, feeling easy or challenging to perform behavior. Perception is often caused by individual confidence or ability when a person believes that he/she could perform behavior will show a positive influence on actions. On the other hand, if he/she believes that cannot act or when the act, will encounter obstacles that show negative impact on the action.

The perceived control of individual behavior in becoming a digital startup can be determined by the person perceiving that anyone has sufficient budget to invest in doing business. If there is not enough budget, it will be recognized on presenting to venture capital or investors to support its own business. Each of them thinks that a person could manage and remain in a stressful environment such as reducing profits or facing competitors. The person feels that he/she could be an organization executive to manage employees in an organization. The person could manage their business under the differences in knowledge and job characteristics of an individual. The person feels of needing to build good relationships and has business partners even if competitors [22]-[25]. Therefore, the researcher has determined the research hypothesis as follows:

H3: Perceived behavioral control positively affects intention to become digital startups.

Finally, the model TPB has been used to determine the relationship between attitude toward the behavior, subjective norm, perceived behavioral control, and intention to become digital startups. (see Fig. 2)

\section{Data collection and Analysis}

All variables in this study are measured by seven-point scale ranging from strongly disagree (1) to strongly agree (7) [26]. These scales were used to measure the relationship level between independence factors (attitude toward the behavior, subjective norm, and perceived behavioral control) and dependence

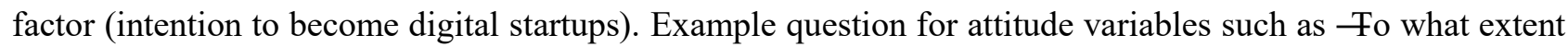
have you considered being a startup does not require much investment?", Fo what extent have you considered being a startup makes success more quickly?" The example questions for subjective norm variables such as" To what degree would your family members encourage you to be a digital startup?" and - Howimportant would your best friends' opinion be regarding you establishing your business?" Example questions for perceives behavioral control variables like $-\Phi$ what degree would you think you can control yourself to drive the digital startup business despite in pressure situations, such as profits decreasing, facing competitors?", - Fo what degree would you can control yourself to make good relationships with business partners although those partners are your competitors?".

Data collection in this research was based on a convenience sampling of 400 undergraduate students from 4 universities in the central region of Thailand. The researcher assigned undergraduate students to be a sample group because they are entering a career. According to the report from Harvard business review [27] addressed that "when you look at success rates conditional on actually starting a company, the evidence against youthful entrepreneurial success becomes even sharper." Therefore it can be clearly defined that young people have higher growth rates for businesses than another group. 
The researcher has determined the method of testing the hypothesis by using multiple linear regression as predictive analysis. The multiple linear regression proposes for explaining the relationship between one dependent variable and two or more independent variables. Moreover, VIF and tolerance value were examined to check multicollinearity as presented in Table 1.

\section{Research Result}

The model of multiple linear regression analysis predicts a future value of the intention to become digital startups meanwhile attitude toward the behavior, subjective norm, and perceived behavioral control were predictors variable. (Table 1.)

Table 1: Results of hypothesis testing the intention to become digital startups

\begin{tabular}{|l|c|c|c|c|c|c|}
\hline \multicolumn{1}{|c|}{ Hypotheses } & Beta & $\mathrm{t}$ & Sig & VIF & Tolerance value & Results \\
\hline $\begin{array}{l}\text { H1: Attitude toward the behavior positively } \\
\text { affects intention to become digital startups. }\end{array}$ & .127 & 2.189 & $.029^{*}$ & 2.417 & .414 & Accepted \\
\hline $\begin{array}{l}\text { H2: Subjective norm positively affects } \\
\text { intention to become digital startups. }\end{array}$ & .417 & 7.039 & $.000^{*}$ & 2.516 & .397 & Accepted \\
\hline $\begin{array}{l}\text { H3: Perceived behavioral control positively } \\
\text { affects intention to become digital startups. }\end{array}$ & .160 & 2.673 & $.008^{*}$ & 2.582 & .387 & Accepted \\
\hline
\end{tabular}

$*$ Significance level at 0.05 , standard error of the estimate $=1.062, \mathrm{R}^{2}=0.417, \mathrm{R}^{2}$ adjusted $=0.413, \mathrm{Sig} . \mathrm{F}=$ 0.000

$\mathrm{R}^{2}$ adjusted was 0.413 means that the attitude toward the behavior, subjective norm, and perceived behavioral control could explain the intention to become digital startups about $41 \%$. The most influential factor for becoming digital startups was the subjective norm while the perceived behavioral control and attitude toward the behavior follow.

\section{Conclusion and Discussion}

The hypothesis testing showed that regression analysis supported all hypotheses. The theory of planned behavior was supported by the research samples. It was found that the research results were consistent with the results from other research studies [7], [25], [28]. They found that attitude toward the behavior, subjective norm, and perceived behavioral control affected intention to become digital startups. The findings from this study suggest that the government, public and private sectors, educators, and policymaker should encourage a positive attitude toward digital startups by creating an environment for learning, startup contests, startup incubators, and developing more digital startup training programs [5], [6], [8]. There will be places for sharing stories, looking for business partners, getting inspirations, and attracting ventures capitals and investors to transform ideas to be realities [28]. Moreover, the result shows that subjective norm positively affects intention means surrounding with reference groups who have a positive attitude towards startups will leverage more intention to become startups.[5], [23], [25]. Lastly, for further research, by using the social cognitive career theory: SCCT to explain how individual form career interests [29] and adding some variables such as variables which related to digital business experience, cultures, gender, and academic business training [5], [28]. Furthermore, collecting data from other sample groups like non-students, working people to analyze the differences between the groups.

\section{References}

[1] A. Salamzadeh and H. Kawamorita Kesim, The enterprising communities and startup ecosystem in Iran,” $J$. Enterprising Communities People Places Glob. Econ., vol. 11, no. 4, pp. 456-479, Jun. 2017.

[2] J.-C. Spender, V. Corvello, M. Grimaldi, and P. Rippa, Startups and open innovation: a review of the literature,” Eur. J. Innov. Manag., vol. 20, no. 1, pp. 4-30, Dec. 2016.

[3] Ministry of Commerce, —Cretive Economy Seminar and Workshop Project,” 2015. [Online]. Available: https://www.moc.go.th/index.php/moc-news/2015-10-19-04-33-08/item/moc-039.html.

[4] The secretariat of the house of representatives, Important and urgent reform agenda of Thailand." 2017.

[5] A. Fernández-Laviada, I. R. Sampedro, and A. Herrero Crespo, Entrepreneurial intention: perceived advantages and disadvantages," Acad. Rev. Latinoam. Adm., vol. 27, no. 2, pp. 284-315, Jul. 2014. 
[6] Mai Ngoc Khuong and Nguyen Huu An, The Factors Affecting Entrepreneurial Intention of the Students of Vietnam National University_ A Mediation Analysis of Perception toward Entrepreneurship," vol. 2016, no. 2, 2016.

[7] A. Naia et al., Entrepreneurial intentions of Sport Sciences students And Theory of Planned Behavior," Mot. Rev. Educ. Física, vol. 23, no. 1, pp. 14-21, Mar. 2017.

[8] M. Hasan Mobaraki, J. Yadollahi Farsi, M. Reza Zali, and R. Molaei, The impact of entrepreneurial ideas and cognitive style on students entrepreneurial intention,” J. Entrep. Emerg. Econ., vol. 6, no. 2, pp. 140-162, May 2014.

[9] M. D. Canever, M. R. M. Barral, and F. G. Ribeiro, How does the public and private university environment affect students' entrepreneurial intention?," Educ. Train., vol. 59, no. 6, pp. 550-564, May 2017.

[10] Startup Thailand Center, National Innovation Agency, Startup Ecosystem," www.startupthailand.org, 2019. [Online]. Available: https://ecosystem.startupthailand.org/.

[11] Ministry of Industry, Thailand, Thailand Industrial Development Strategy 4.0.”2017.

[12] Techsauce, Đigital Startup Ecosystem Builder,” Techsauce, 04-Oct-2018. .

[13]S. J. H. Graham and T. S. Sichelman, Intellectual Property and Technology Startups: What Entrepreneurs Tell Us," in Technological Innovation: Generating Economic Results, vol. 26, 0 vols., Emerald Group Publishing Limited, 2016, pp. 163-199.

[14] Business Sweden Thailand, Thailand as Sea’s Emerging Startup Hub.” 2018.

[15] Young Entrepreneur Council, — Ae You Building A Small Business - Or A Startup?,” 2012. [Online]. Available: https://www.forbes.com/sites/theyec/2012/08/15/are-you-building-a-small-business-or-a-startup/\#17b42b4fa528.

[16] T. Ljungkvist, -Costructive business advice? Different trajectories between family businesses and startups,” $J$. Fam. Bus. Manag., vol. 7, no. 3, pp. 309-328, Aug. 2017.

[17] Richard Harroch, -AGuide to Venture Capital Financings for Startups,” 2018. [Online]. Available: https://www.forbes.com/sites/allbusiness/2018/03/29/a-guide-to-venture-capital-financings-forstartups/\#79e34b2351c9.

[18] Asian Development Bank, Thailand: Economy | Asian Development Bank,” 2019. [Online]. Available: https://www.adb.org/countries/thailand/economy.

[19] A. Pisoni and A. Onetti, When startups exit: comparing strategies in Europe and the USA," J. Bus. Strategy, vol. 39, no. 3, pp. 26-33, May 2018.

[20] I. Ajzen, The theory of planned behavior,” Theor. Cogn. Self-Regul., vol. 50, no. 2, pp. 179-211, 1991.

[21] Icek Ajzen, Constructing a Theory of Planned Behavior Questionnaire.” 2019.

[22] Leong Chee Keong, Entrepreneurial Intention: An Empirical Study among Open University Malaysia Students," Centre for Graduate Studies, Open University Malaysia, 2008.

[23] Paul Weiss, Entrepreneurial Intentions among Dutch and Indonesian university students,” Tilburg University, 2015.

[24] Francisco Liñán and Yi-Wen Chen, - Festing the Entrepreneurial Intention Model on a Two-Country Sample." 2006.

[25] F. Bizarrias, H. Magalhães Olivense do Carmo, and A. Silveira, Entrepreneurial Intention of the Participants of the Startup Weekend: Longitudinal Analysis," International Journal of Advances in Management and Economics, vol. 6, no. 1, Jan. 2017.

[26] Uma Sekaran, Research Methods for Business: A Skill-Building Approach. New York: John Wiley \& Sons, 2003.

[27] P. Azoulay, B. Jones, J. D. Kim, and J. Miranda, Research: The Average Age of a Successful Startup Founder Is 45," Harvard Business Review, 11-Jul-2018.

[28] S. Sabah, Entrepreneurial Intention: Theory of Planned Behaviour and the Moderation Effect of Start-Up Experience," 2016.

[29] A. T. P. Tran and H. Von Korflesch, -Aconceptual model of social entrepreneurial intention based on the social cognitive career theory," Asia Pac. J. Innov. Entrep., vol. 10, no. 1, pp. 17-38, Dec. 2016. 